\title{
OPTIMASI PENGGUNAAN SELACTION UNTUK PENGHEMATAN ENERGI LISTRIK
}

\author{
I Gusti Made Ngurah Desnanjaya1), I Wayan Dani Pranata2) \\ 1,2Program Studi Sistem Komputer,STMIK STIKOM Indonesia Denpasar, Indonesia \\ Email: ngurah.desnanjaya@stiki-indonesia.ac.id, pranatadani92@gmail.com
}

\begin{abstract}
ABSTRAK
Penggunaan energi listrik secara efisien masih kurang dilakukan, dikarena masih sering dijumpai pemakaian energi yang tidak efisien. Setengah dari pemakaian daya listrik pada rumah dan di bangunan gedung perkuliahan atau perkantoran terdapat pada AC. Untuk mensukseskan efisien energi secara keseluruhan perlu dilakukan dukungan perilaku, kebiasaan, dan kesadaran umum tentang penghematan energi ini perlu dilakukan. Maka dilakukan penelitian dengan menggunakan sistem control SELACTION (safety energi listrik air conditioning) automatis yang dapat merespon pergerakan dan panas tubuh manusia. Sensor Passive Infrared Receiver atau yang dikenal dengan PIR memancarkan gelombang dan memberikan signyal apabila terdapat gerakan pada jangkauan pembacaan sensor, kemudian signyal diteruskan ke mikrokontroler dan memberikan output signyal ke rangkaian kontrol AC split. Apabila suhu pada ruangan tidak sesuai dengan yang diinginkan, pengguna dapat merubah pada perangkat SELACTION sesuai dengan dibutuhkan pengguna, agar tidak mengurangi rasa kenyamanan pengguna. Pembuatan rancang bangun sistem SELACTION untuk penghematan energi listrik yang dilakukan dapat melakukan aktif/nonaktif automatis, serta mengatur suhu secara otomatis pada AC dengan perangkat yang portable. Alat SELACTION automatis ini ialah bekerja pada saat merespon aktifitas manusia dalam sebuah ruangan. Maka dalam penelitian ini difokuskan pada penghematan yang dapat dilakukan dengan mempergunakan alat SELACTION. Menggunkan uji experimen dengan variabel yang sama dan menggunakan uji komperatif uji t. Uji komparatif digunakan untuk mencari dan mengerti kaitan antara variabel dalam panelitian, agar medapatkan selisih penghematan energi listrik yang dapat dilakukan dengan menggunakan alat SELACTION.
\end{abstract}

Kata kunci: AC (Air Conditioning), SELACTION, Penghematan, Energi, Listrik, Mikrokontroler

\begin{abstract}
The efficient use of electrical energy is still lacking, because there are still often inefficient energy uses. Half of the electrical power usage in homes and in building lectures or office buildings is in the air conditioner. To succeed in overall energy efficiency it is necessary to support behaviors, habits, and general awareness about saving energy. Then a study was conducted using an automatic SELACTION (electric energy air conditioning) control system that can respond to human body movement and heat. Passive Infrared Receiver sensor or known as PIR emits waves and gives a signal when there is movement in the sensor reading range, then the signal is transmitted to the microcontroller and gives a signal output to the AC split control circuit. If the temperature in the room is not what you want, the user can change the SELACTION device according to user needs, so as not to reduce the user's sense of comfort. The design of the SELACTION system for saving electricity can be done automatically or inactive, as well as regulating the temperature automatically on the air conditioner with a portable device. This automatic SELACTION tool is working when responding to human activities in a room. So in this study focused on savings that can be done by using the SELACTION tool. Using an experimental test with the same variables and using the comparative test $t$ test. Comparative tests are used to find and understand the relationship between variables in research, so as to obtain the difference in electrical energy savings that can be done using the SELACTION tool.

Keywords : AC (Air Conditioning), SELACTION, Savings, Energy, Electricity, Microcontrolle
\end{abstract}




\section{PENDAHULUAN}

Suatu sistem pengkondisian udara, atau yang sering disebut HVAC (Heating, Ventilating, Air Conditioning) meliputi suatu sistem motor, saluran pipa, sistem pertukaran udara, panas, dan sistem kontrol. Sistem dari HVAC dipergunakan untuk mengatur aliran udara pada komponen agar mendapatkan kondisi yang diinginkan oleh user [1]. Menyediakan kualitas udara yang baik merupakan tugas utama dari HVAC, HVAC merupakan mengusir bau dan debu agar kenyamanan user tetap terjaga dan sistem pada HVAC juga dapat melindungi area dan ruangan-ruangan agar tetap bersih [2]. Sistem HVAC termasuk salah satu yang berkontribusi pada konsumsi energi listrik secara signifikan pada suatu bangunan gedung. Dengan demikian, sistem HVAC merupakan suatu yang sangat penting untuk dilakukan pada proses managemen energi. Dengan penggunaan sistem HVAC secara tepat, maka akan dapat menaikkan operasional dan dapat pula menekan penggunaan dari energi serta mengurangi biaya. AC split membagi antara sisi panas dan sisi dingin pada sistem. Sisi yang dingin terdiri atas katup ekspansi dan kumparan evaporator yang pada umumnya diletakkan pada suatu Air Handler Unit (AHU) [3]. AHU menghembuskan udara melalui kumparan evaporator dan udara, setelah melewati kumparan evaporator akan menjadi dingin. Udara dingin ini selanjutnya diteruskan ke ruangan yang berada pada gedung didinginkan. Sedangkan sisi panas yang kerap disebut dengan unit kondensasi atau kondenser umumnya ditempatkan di luar dari suatu bangunan [3][4]. Unit kondensor ini seperti terlihat pada Gambar 1.

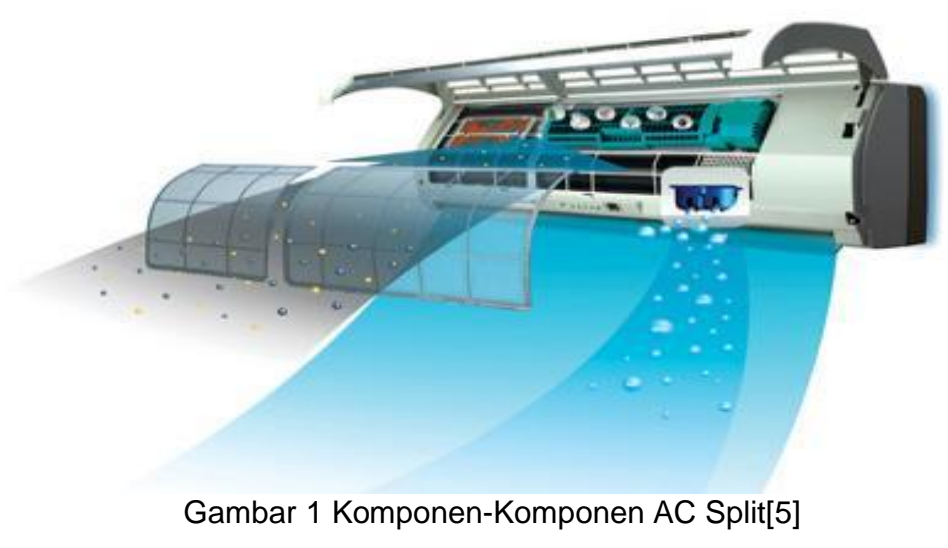

Pengunaan air conditioning pada suatu bangunan gedung memberikan kontribusi besar bagi penggunaan energi listrik. Pada penelitian ini dilakukan pengujian pada ruangan laboratorium Sistem Kendali Teknik Elektro Univeristas Udayana. Saat AC dalam ruangan tidak pernah dimatikan dan kondisi suhu luar ruangan yang mengakibatkan kinerja AC lebih berat mengakibatkan konsumsi energi listrik cukup besar. Maka dibuat suatu penelitian menggunakan SELECTION untuk mengetahui pengaruh penghematan energi dan kenyamanan user. Pada penelian sebelumnya, peneliti melakukan pengujian pada alat SELACTION dengan melakukan control Air Conditioning, sensor, dan informasi pada LCD[6]. Terdapat penelitan terkait dengan penggunaan hadware dan sistem penghematan listrik, pada penelitian yang dilakukan oleh Almanda dkk yang bertujuan untuk mengatur konsumsi energi listrik pada power peralatan listrik pada sebuah ruangan[7]. Penelitian lain yang dilakukan oleh Utama dkk dengan melakukan perhitungan penggunaan aplikasi agar mendapatkan penghematan energi listrik [8]. Perbandingan yang dilakukana antara penelitian yang sudah ada dengan penelitian ini ialah dengan melakukan kontol air conditioning dan menaikan atau menurunkan suhu sesuai dengan kenyamanan dari user, serta mengukur penghematan yang dilakukan dengan menggunakan perhitungan variable sebelum dan sesudah menggunakan SELECTION yang dipengaruhi kondisi suhu diluar ruangan.

\section{A. Cara Menentukan Kapasitas AC Sesuai Ruangan}

Kapasitas $A C$ yang tepat dengan ruangan sangat penting untuk diperhatikan karena erat hubungannya dengan energi listrik yang akan digunakan. Pemakaian listrik akan menjadi boros apabila Unit AC yang digunakan sangat besar dibandingkan dengan luas dari ruangan, begitu pula dengan penggunaan unit yang sangat kecil. Penggunaan unit air conditioner yang sangat kecil dibanding dengan luas dari ruangan akan menyebabkan waktu yang dibutuhkan untuk mendinginkan ruangan menjadi lama, tentunya hal ini dapat mengakibatkan tagihan listrik menjadi besar. PK (Paard 
Kracht / Daya Kuda / Horse Power $(H P)$ ) pada $A C$ merupakan satuan daya yang digunakan pada compressor AC. PK lebih umum digunakan jika dibandingkan dengan BTU/h [9].

Penggunaan mesin $A C$ unit terpisah memberikan kenyamanan lebih karena suara disisi dalam ruangan lebih halus dan tidak berisik. Besarnya daya mesin $A C$ disebutkan dalam satuan $P K$, akan tetapi yang lebih tepat kapasitas pendinginnya dinyatakan dalam satuan Btu/h atau $\mathrm{Kcal} / \mathrm{h}$. Secara mudah arus pada tegangan $220 \mathrm{~V}$, fase 1 dan ruang yang dapat didinginkan dalam penggunaan biasa adalah jika diisi sejumlah orang yang wajar tanpa sumber panas yang berarti seperti pada tabel berikut [4][10].

Tabel 1 Kapasitas Daya Mesin AC[11]

\begin{tabular}{ccccc}
\hline $\begin{array}{c}\text { Daya } \\
(P K) .\end{array}$ & $\begin{array}{c}\text { Arus Satu Fase } \\
(\mathrm{A})\end{array}$ & Btu/h & Kcal/h & $\begin{array}{c}\text { Luas Ruangan } \\
(\mathrm{m})\end{array}$ \\
\hline $1 / 2$ & 2,9 & 5.000 & 1.260 & $12 \mathrm{~m}^{2}, 3 \times 4 \mathrm{~m}$ \\
$3 / 4$ & 3,7 & 7.000 & 1.890 & $18 \mathrm{~m}^{2}, 4 \times 4,5 \mathrm{~m}$ \\
1 & 5,2 & 9.000 & 2.520 & $24 \mathrm{~m}^{2}, 6 \times 4 \mathrm{~m}$ \\
$11 / 2$ & 7,3 & 12.000 & 3.780 & $36 \mathrm{~m}^{2}, 6 \times 6 \mathrm{~m}$ \\
\hline
\end{tabular}

Dengan meningkatnya teknik efisiensi mesin $A C$ sehingga dengan daya $1 P K$ dapat diperoleh pendinginan sampai dengan $12.000 \mathrm{Btuh} / \mathrm{h}$. Mesin $A C$ fase satu biasanya dilengkapi dengan kabel fleksibel dan tusuk kontak dengan tiga kontak termasuk kontak pengaman

Adapun perkiraan kebutuhan pengkondisian ruangan atau perangkat Air Conditioner Cooling Load adalah sebagai berikut [12] [13]:

1. Kebutuhan pengkondisian (AC Cooling Load) di dalam suatu ruangan dipengaruhi oleh :

a. Volume dan spesifikasi ruangan (tembok, kaca, kayu dan lain-lain).

b. Jumlah kalori yang ditimbulkan oleh material pengisi ruangan (perangkat dan material penunjang lainnya).

2. Perkiraan kebutuhan cooling load adalah sebagai berikut :
a. Manusia
: 250 - 760 Btuh / orang.
b. Ruang rapat
(pria $=760$ Btuh, wanita $=680$ Btuh).
c. Ruangan kosong
: $500-750$ Btuh $/ \mathrm{m}^{3}$ (ideal).
: $150-400$ Btuh / $\mathrm{m}^{3}$.

3. Rumus perhitungan Cooling Load $(C L)$ :

$$
C L R=P \times L \times T \times\left(\frac{\text { Kebutuhan CLR }}{m^{3}}\right)
$$

4. Asumsi dan konversi :
a. L
: Lebar ruangan
b. $\mathrm{T}$
c. $\frac{\text { Kebutuhan CLR }}{m^{3}}$
: Tinggi ruangan
: 150 Btuh/m

\section{B. Mikrokontroller AVR ATmega16}

AVR adalah seri mikrokontroler CMOS 8-bit yang dibuat oleh Atmel, dengan berbasis arsitektur RISC (Reduced Instruction Set Computer) [6][14]. instruksi yang terdapat pada mikrokontroler akan dieksekusi dalam satu siklus clock AVR yang memiliki 32 register generalpurpose, timer/counter fleksibel dengan mode compare, interrupt internal dan eksternal, serial UART, programmable Watchdog Timer, mode power saving, ADC dan PWM internal. ATMega16 mempunyai throughput hampir mencapai 1 MIPS per $\mathrm{MHz}$ yang menyebabkan disainer sistem untuk mengoptimasi pemakaian daya berbanding kecepatan proses [15]. 


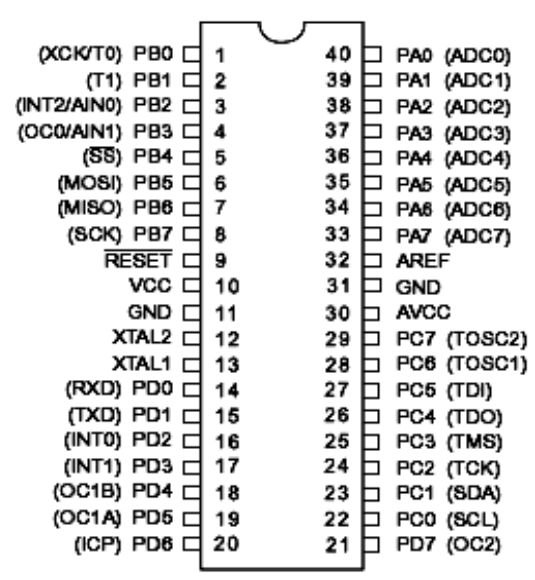

Gambar 2 Pin - pin Atmega 16[16]

ATmega16 terdapat empat buah port meliputi PortA, PortB, PortC, dan PortD. Keempat port menggunakan jalur bidirectional dengan pilihan internal pull-up. Pada setiap port terdapat tiga buah register bit, yaitu DDxn, PORTxn, dan PINxn. Huruf x sebagai ganti nama huruf dari port sedangkan huruf $n$ sebagai ganti nomor bit. Pada $\mathrm{I} / \mathrm{O}$ address DDRx didalamnya terdapat bit DDxn, pada I/O address PORTx didalamnya terdapat bit PORTxn, dan pada I/O address PINx didalamnya terdapat bit PINxn. Arah pin dari register DDRx (Data Direction Regiter) ditentukan oleh Bit DDxn. Px akan berfungsi sebagai pin output ketika DDxn diset 1. Px akan berfungsi sebagai pin input ketika DDxn diset 0 . Resistor pull-up akan aktif bila PORTxn diset 1 pada saat pin terkonfigurasi sebagai pin input. Untuk menonaktifkan resistor pull-up, PORTxn harus diset 0 atau pin dikonfigurasi sebagai pin output. Sesudah kondisi reset maka pin port merupakan tri-state, pin port akan berlogika 1 bila PORTxn diset 1 pada saat pin terkonfigurasi sebagai pin output. Pin port akan berlogika 0 bila PORTxn diset 0 pada saat pin terkonfigurasi sebagai pin output.[17].

Biasanya, kondisi pull-up enabled dapat menjadikan mikroprosesor lebih fleksibel atau dapat diseuaikan dengan kebutuhan dari pengguna.[17]

Tabel 2 Konfigurasi port [18]

\begin{tabular}{cccccl}
\hline DDxn & PORTxn & $\begin{array}{c}\text { PUD } \\
\text { (in SFIOR) }\end{array}$ & I/O & Pull-up & Comment \\
\hline 0 & 0 & $\mathrm{x}$ & Input & No & Tri-state (Hi-Z) \\
0 & 1 & 0 & Input & Yes & $\begin{array}{l}\text { Pxn will source current if ext. } \\
\text { pulled low }\end{array}$ \\
0 & 1 & 1 & Input & No & Tri-state (Hi-Z) \\
1 & 0 & $\mathrm{x}$ & Output & No & Output Low (Sink) \\
1 & 1 & $\mathrm{x}$ & Output & No & Output High (Source) \\
\hline
\end{tabular}

Bit 2 - PUD : Pull-up Disable terjadi ketika bit diset bernilai 1 maka pull-up pada port I/O akan dinonaktifkan walaupun register DDxn dan PORTxn dikonfigurasikan untuk menyalakan pull-up (DDxn=0, PORTxn=1)[18][14]:

a. Mikrokontroler AVR 8 bit berdaya rendah dan performa tinggi.

b. Arsitektur RISC

1. 131 Instruksi standar, rata-rata dieksekusi dalam satu clock cycle

2. $32 \times 8$ Register standar

3. Dapat bekerja sampai 16 MIPS (Mega Instruction Per Seccond) pada $16 \mathrm{MHz}$

4. Memiliki 2 buah multiplier

c. Memori Program dan Memori Data

1. $16 \mathrm{~K}$ Bytes In System Self Programmable Flash yang mampu ditulis dan bACa sampai 10,000 kali.

2. 512 Bytes EEPROM yang mampu ditulis dan bACa sampai 100,000 kali.

3. 512 Byte Internal SRAM.

d. Periperal dan Fitur

1. Dua Timer / Counter 8-bit dengan prescaler terpisah dan compare mode. 
2. Satu Timer / Counter 16-bit dengan prescaler terpisah, compare mode, dan capture mode.

3. Real Time Counter dengan oscillator terpisah.

4. Empat channel PWM.

5. 8 Channel ADC, dengan tingkat ketelitian 10-bit.

6. Serial USART yang dapat diprogram dengan kecepatan sampai 2,5 Mbps.

7. Komparator analog.

8. Memiliki 32 buah saluran I/O meliputi Port A, Port B, Port C, Port D.

\section{SELACTION}

Rancang bangun sistem SELACTION untuk penghematan energi listrik ini dirancang sebagai suatu sistem yang dapat membantu pengguna untuk mengaktifkan dan menonaktifkan $A C$. Sehingga memungkinkan pengguna untuk melakukan penghematan energi listrik secara langsung terhadap air conditioning yang aktif terus-menerus tanpa adanya pengguna didalam ruangan, mengharuskan pengguna untuk mematikan air conditioning, maka digunakanlah rancang bangun sistem control air conditioning untuk penghematan energi listrik yang dapat dipergunakan secara outomatis tanpa bantuan pengguna. Dalam perancangan sistem ini, sudah berhasil dibuat sistem kontrol model atau prototipe control $A C$ dan sudah dapat berfungsi dengan baik. Pada dasarnya semua aplikasi terpusat pada modul mikrokontroler. Pengujian sistem dilakukan untuk mengetahui bagaimana sistem bekerja, fungsi kontrol melalui mikrokontroler, kendali, dan fleksibilitas sistem. Sistem yang telah dihasilkan sudah bekerja sesuai dengan tujuan yang hendak dicapai yang terdapat pada penelitain sebelumnya[6].

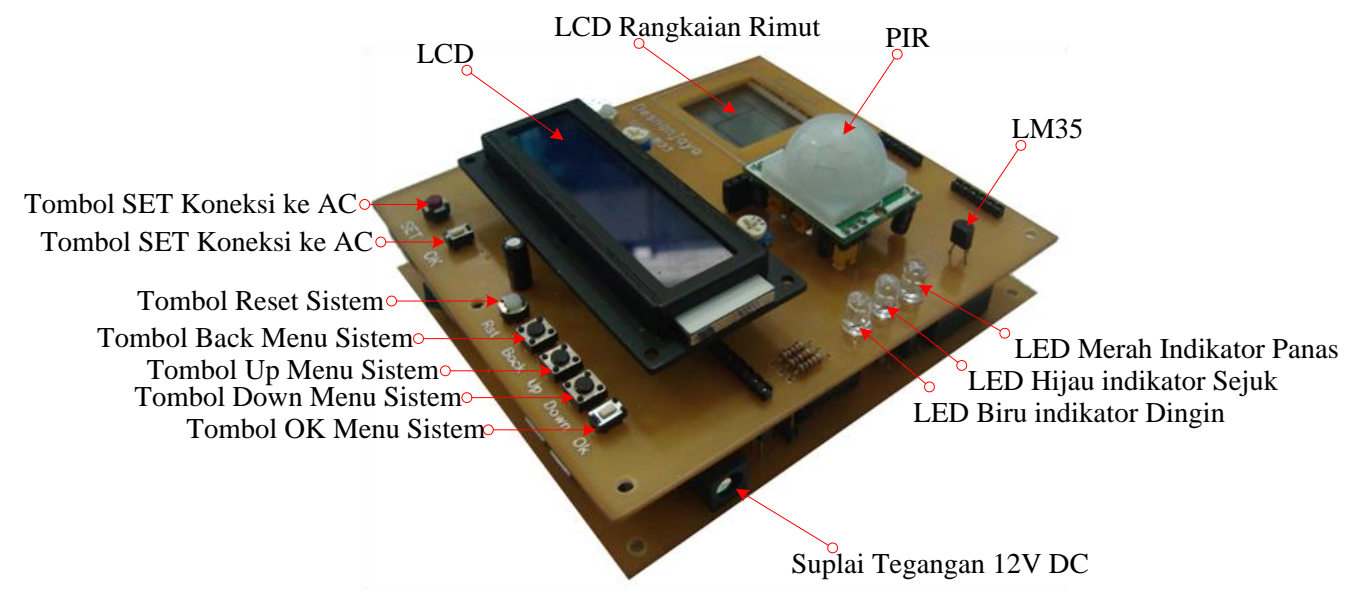

Gambar 3 SELACTION [6]

Sistem ini menggunakan inti, yaitu sebuah mikrokontroler ATmega16 yang berisikan program agar dapat terkoneksi dengan $A C$, dan penghubung antara $A C$ dengan modul sistem control air conditioning. Fungsi dari modul ini sebagi alat yang digunakan untuk menghubungkan secara langsung dengan air conditioning yang akan di control. Modul inilah yang mengirimkan instruksi dalam suatu format data ke dalam program didalam mikrokontroler. Sistem ini wajib mempunyai tempat khusus didalam ruangan agar dapat mengontrol air conditioning (agar tidak ada benda yang menghalangi modul sistem control $A C$ ). Sehingga sistem ini dapat bebas dari benda-benda yang menghambat sistem untuk membaca lingkungan sekitarnya.

Pada sistem ini ada tiga jenis pengguna yang dibedakan menjadi pendeteksian keberadaan manusia, pengontrolan $A C$, dan pengaturan suhu. Hak akses yang dimiliki setiap prosedur berlainan terhadap sistem ini. Pendeteksian keberadan manusia yang mempunyai status mengobservasi lingkungan atau ruangan sesuai dengan cangkupan sistem, ketika terdapat keberadaan manusia maka akan terjadi pemberian sinyal high atau low dari sistem ini. Pendeteksian keberadan manusia mempunyai andil yang sangat penting ketika akan menentukan tindakan berikutnya setelah sistem memberikan sinyal ke mikro. Pendeteksian keberadaan manusia juga memiliki akses untuk memberikan perintah tindakan selanjutnya pada sistem. Selanjutnya adalah Pengontrolan AC. Sistem ini akan bekerja setelah mendapat sinyal dari pendektesian keberadan manusia. Akses yang dimiliki oleh Sistem pengontrolan $A C$ hanya untuk memberikan perintah dan membaca data dari sistem yang akan diberikan oleh penditeksian keberadan manusia. Yang paling akhir yaitu sebagai Pengaturan 
suhu. Sistem ini menerima masukan berupa signyal dari sensor dan membaca kondisi dari lingkungan atau ruangan yang diobservasi, kemudian signyal di proses mengarah ke sistem mikro dan diproses selanjutnya signyal diberikan kepada pengontrolan $A C$.

\section{Wattmeter DIGILIFE tipe DL8}

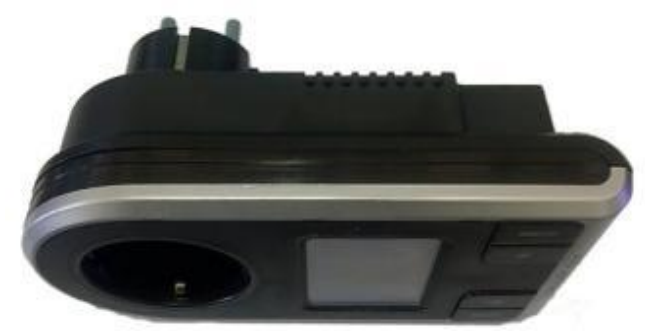

Gambar 4 Wattmeter DIGILIFI tipe DL8

Fungsi dari wattmeter DIGILIFI tipe DL8 adalah untuk mengetahui pengunaan daya listrik alatalat elektronik yang dipergunakan. Cara mengunakan alat ini sangatlah mudah, yaitu dengan menyambungkan alat elekronik ke soket wattmeter [19]. Pengukuran watt, kwh, voltase, ampere PLN (Perusahaan Listrik Negara) dapat terlihat di layar. European standard and quality manual available in English-Deutsch spec:
a. AC voltage
b. Maximum Power
$: 230 \mathrm{~V} / 50 \mathrm{~Hz}$
c. Konsumsi Listrik / Watt-hour
: Sampai 16A / 3680W
d. Max record time
: 0.0001 sampai $999.9 \mathrm{kWh}$
e. Buzzer alert for overload warning
f. Backlight untuk memudahkan membaca
g. Accuracy $\pm 3 \%$

Terdapat tiga display panel pada Tipe DL8 [19] :
a. Panel Atas
: Volt(V), Ampere(A), Max Ampere, Max Watt, Set
b. Panel Tengah overload Ampere/Watt
c. Panel Bawah
: Konsumsi energy $(\mathrm{kWh})$, biaya $(\$ / \mathrm{kWh})$, Total Cost $(\$)$
: Waktu Penggunaan

\section{METODE}

Penelitian ini merupakan penelitian eksperimental, dengan treatment by subject design. Penelitian yang dapat digunakan sebagai sebuah studi yang objektif, sistematis, dan terkontrol untuk memperhitungkan atau mengendalikan fenomena dapat disebut penelitian eksperimental. Tujuan penelitian eksperimen adalah untuk meneliti hubungan dari sebab akibat, hasilnya dibandingkan satu sama lain dengan variable yang sama. Pada umumnya penelitian eksperimental dilakuakan dengan menempuh langkah-langkah sebagai berikut. Melaksanakan kegiatan kajian secara induktif yang berhubungan dengan persoalan yang akan di pecahkan. Mengidentifikasi dan mendeskripsikan masalah. Melaksanakan kegiatan studi literature dan beberapa sumber yang bersangkutan, menentukan variable, melaksanakan eksperimen. Mengumpulkan data kasar dan proses eksperimen. Memaparkan data yang tepat dengan variable yang telah ditentukan. Menganalisis data dan melaksanakan tes signifikansi dengan teknik statistik yang relevan

\section{A. Teknik Pengumpulan Data}

Teknik pengumpulan data dalam penelitian ini diperoleh berdasarkan metode seperti berikut: 1. Metode eksperimen.

Dalam metode ini penelitian dilakukan dilakukan di Laboratorium Teknik Kendali Teknik Elektro Kampus Bukit Jimbaran Universitas Udayana. Dalam penelitian ini terdapat perlakuan (treatment), sehingga dalam metode ini berfungsi untuk menemukan dampak dari perlakuan tertentu kepada yang lain pada saat kondisi terkendalikan. Bentuk eksperimen yang digunakan adalah Pre-Experimental Designs dengan One-Group Pretest-Posstest Design. Dalam eksperimen ini terdapat variabel-variabel luar yang turut berdampak kepada terciptanya variabel dependen. Dalam metode ini terdapat perbandingan antara sebelum perlakukan dan sesudah perlakuan, dengan demikian hasil dari perlakuan dapat dilihat lebih akurat. Bentuk hubungannya: 
Dimana:

\section{Metode Observasi}

$\mathrm{O}_{1}$ : sebelum perlakuan

$\mathrm{O}_{2}$ : setelah perlakuan

Pengaruh terhadap perlakuan $=\left(\mathrm{O}_{2}-\mathrm{O}_{1}\right)$

Metode penghimpunan data dengan melakukan pengamatan dan peninjauan yang berhubungan dengan penggunaan $A C$ di Laboratorium Teknik Kendali Teknik Elektro Kampus Bukit Jimbaran Universitas Udayana. Observasi yang dilakukan telah dirangcang secara sistematis, tentang apa yang akan diamati, kapan dan dimana tempatnya. Dalam melakukan pengamatan digunakan beberapa instrumen penelitian.

3. Studi Kepustakaan

Metode pengumpulan data yang dilakukan dengan membaca literatur-literatur yang berkaitan dengan penggunaan kontrol $A C$ otomatis

Teknik penentuan sempel dilakukan secara Non Probability Sampling merupakan cara pengambilan setiap elemen dalam populasi belum tentu mempunyai kesempatan sama untuk diseleksi sebagai subyek dalam sampel. Ada intervensi tertentu dari peneliti, peneliti menyesuaikan dengan kebutuhan dan tujuan penelitiannya. Teknik sampling Accidental, artinya siapa saja yang secara tidak sengaja ingen berkunjung ke labolatorium Teknik Kendalai, maka orang tersebut dapat dijadikan sampel. Sempel yang telah diambil dalam satu periode penelitian akan di gunakan kebali pada periode yang berbeda dan hasilnya akan di bandingkan.

\section{B. Variabel Penelitian}

Berdasarkan permasalahan yang telah dijabarkan sebelumnya, maka dalam penelitian ini variabel-variabel dalam analisis diidentifikasikan secara garis besar menjadi tiga variabel, yaitu variabel independen, dependen, dan moderator. Hubungan antara variabel independen, dependen dan moderator dapat dilihat pada gambar berikut ini.

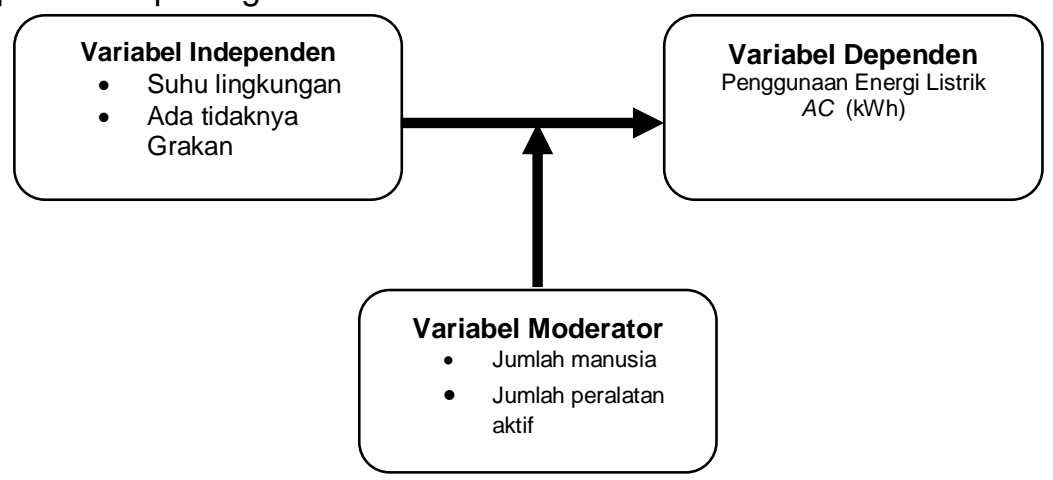

Gambar 5 Hubungan Variabel Independen-Moderator, Dependen

Untuk menghindari kesalahan dalam mengertikan variabel-variabel yang akan diteliti dan menimbulkan pengertian ganda atau ambigu pada saat pengumpulan data, variabel-variabel yang digunakan diidentifikasikan dengan jelas. Difinisi operasional variabel masing-masing variabel tersebut, yaitu sebagai berikut:

1. Variabel Independen:

Variabel suhu ruangan dan ada tidaknya gerakan adalah variabel yang mempengaruhi dan menyebabkan perubahan atau terbentuknya variabel dependen unsur yang terkait dengan penggunaan energi listrik $A C$ (kWh) yang diteliti pada Laboratorium Teknik Kendali Teknik Elektro Kampus Bukit Jimbaran Universitas Udayana. Diukur dengan indikator-indikator sebagai berikut:

Suhu ruangan

: Suhu ruangan dalam penelitian ini diukur menggunakan sensor LM35 yang berfungsi sebagai indikator pengatur suhu $A C$ split yang akan di kontrol mengunakan kontrol $A C$ otomatis

Ada tidaknya gerakan $\quad$ : Ada tidaknya gerakan dalam penelitian ini menggunakan sensor PIR yang akan membaca setiap gerakan pada ruangan yang bertujuan untuk melakuakan eksekusi pada $A C$ apakah $A C$ menyala atau mati.

2. Variabel Dependen: 
Variabel penggunaan energi listrik $A C(\mathrm{kWh})$ adalah variabel yang dipengaruhi atau yang menjadi akibat, karena adanya variabel bebas pada Laboratorium Teknik Kendali Teknik Elektro Kampus Bukit Jimbaran Universitas Udayana. Diukur dengan indikator-indikator sebagai berikut:

Penggunanan energi listrik $A C(\mathrm{kWh})$ : Penggunanan energi listrik $A C(\mathrm{kWh})$ dalam penelitian ini diukur mengunakan wattmeter digilife tipe 8 yang bertujuan untuk mengatahui penggunaan energy listrik pada $A C$ yang di teliti.

3. Variabel Moderator:

Variabel jumlah manusia dan jumlah pralatan aktif adalah variabel yang mempengaruhi baik itu memperkuat atau memperlemah hubungan antara variabel independen dan dependen pada Laboratorium Teknik Kendali Teknik Elektro Kampus Bukit Jimbaran Universitas Udayana. Diukur dengan indikator-indikator sebagai berikut:

Jumlah manusia : Jumlah manusia dalam penelitian ini adalah hasil dari observasi yang bertujuan untuk menggunakan kembali pada priode penelitian selanjutnya agar dapat di bandingkan.

Jumlah pralatan aktif $\quad$ : Jumlah pralatan aktif dalam penelitian ini penelitian ini adalah hasil dari observasi yang bertujuan untuk menggunakan kembali pada priode penelitian selanjutnya agar dapat di bandingkan.

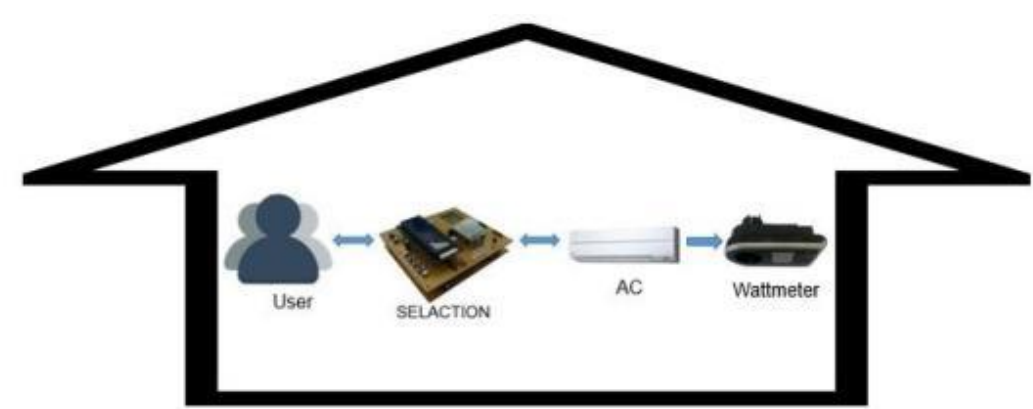

Gambar 6 Gambaran Umum Sistem

\section{Uji Komparatif}

Uji komparatif digunakan untuk mencari dan mengerti hubungan antara variabel dalam panelitian. Uji komparatif yang dilakukan merupakan uji komparatif dari dua kelompok berpasangan, karena berasal dari kelompok data yang sama, yaitu, sebelum menggunakan alat dan sesudah menggunakan alat. Sebelum melakukan uji komparatif, dilakukan Uji Normalitas Data. Uji ini dilakukan untuk mengetahui normalitas distribusi data, dengan melihat hasil dari uji Shapiro-Wilk. Uji ShapiroWilk dipilih karena jumlah sampel kurang dari 50. Jika data yang diperoleh terdistribusi normal, $p>$ 0,05, maka uji hipotesis kompatatif yang dilakukan adalah dengan Uji $\mathrm{t}$ berpasangan (parametrik). Jika tidak, maka digunakan uji alternatifnya, yaitu uji Wilcoxon (uji nonparametrik). Hasil analisis dari uji komparatif akan didapatkan nilai p. Nilai p selanjutnya digunakan untuk menguji hipotesis dan menarik kesimpulan, apakah ada atau tidaknya hubungan antara variabel. Jika nilai $p<0,05$, maka terdapat adanya perbedaan rerata yang bermakna antara dua kelompok data. Pengujian komparatif dilakukan dengan menggunakan program SPSS 16.0 for windows. 


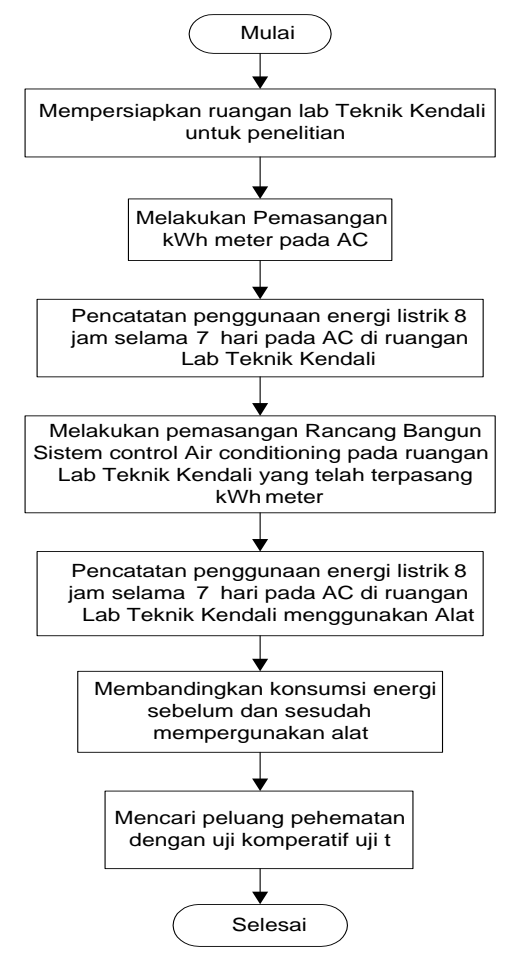

Gambar 7 Alur Analisis Sistem Pengujian

\section{HASIL DAN PEMBAHASAN}

\section{A. Kondisi lingkungan}

Lokasi penelitian di Laboratorium Teknik Kendali yang terletak pada jurusan Teknik Elektro Universitas Udayana Bukit Jimbaran merupakan sebuah laboratorium yang bergerak di bidang teknik kendali yang berkaitan dengan pengaplikasian dari teori pada sistem pengaturan baik itu pengaturan elektris, elektromekanik, pneumatic serta robotik.

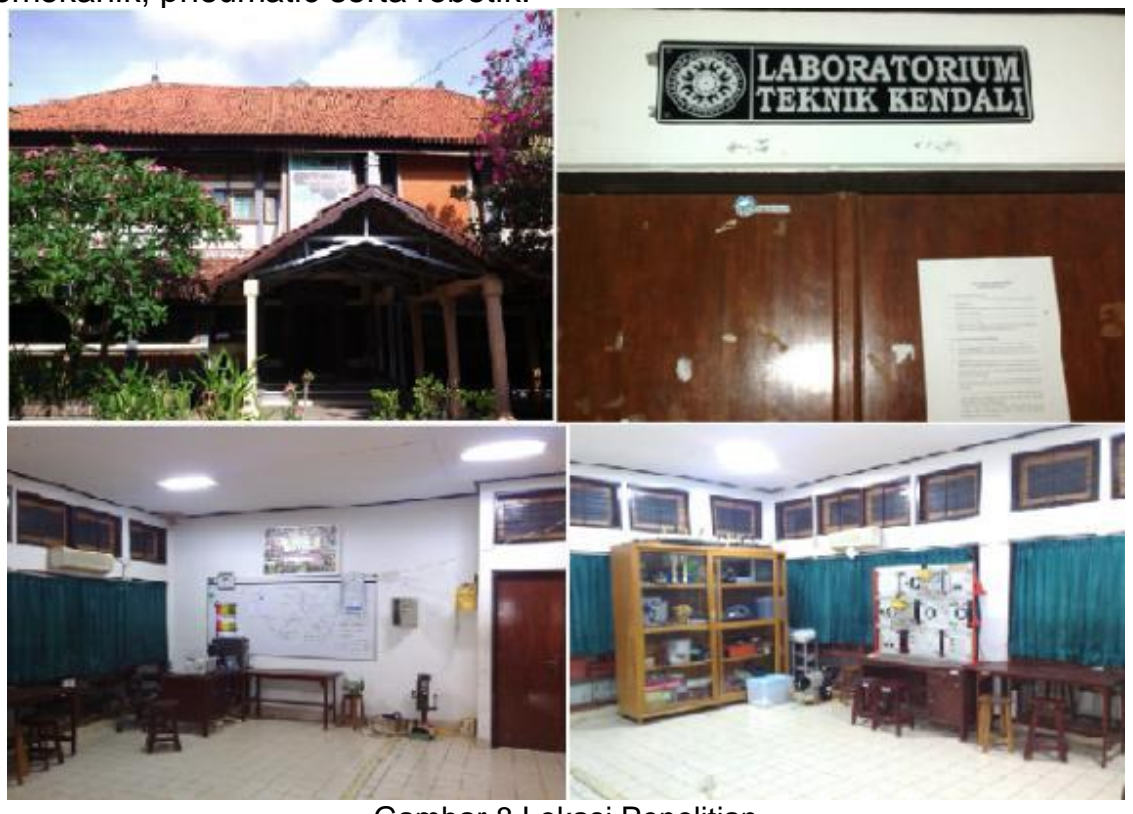

Gambar 8 Lokasi Penelitian

Penelitian ini diukur mengunakan wattmeter digilife tipe 8 yang bertujuan untuk mengetahui jumlah energi listrik yang digunakan pada $A C$ yang diteliti. 


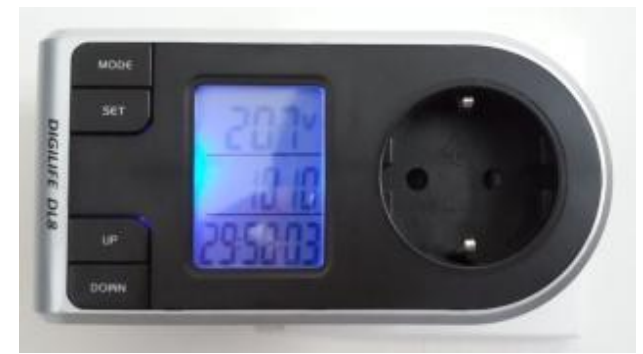

Gambar 9 Wattmeter digilife tipe 8

Pengukuran suhu, kelembaban udara diluar ruangan menggunakan termohigrometer.

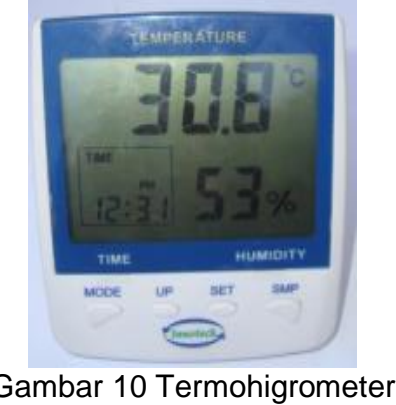

Penelitian ini mengunakan metode observasi. Metode pengumpulan data yang digunakan yaitu dengan melakukan pengamatan dan peninjauan langsung yang berhubungan dengan penelitian. Luas ruangan Laboratorium Teknik Kendali yang terletak pada jurusan Teknik Elektro Universitas Udayana Bukit Jimbaran $5,5 \times 7 \mathrm{~m}^{2}$. Pada penelitian ini tipe $A C$ yang digunakan adalah tipe $A C$ split Toshiba RAS-13YKX yang sudah dipergunakan sejak tahun 2006 hingga sekarang, untuk data lengkap AC dapat di lihat pada lampiran.

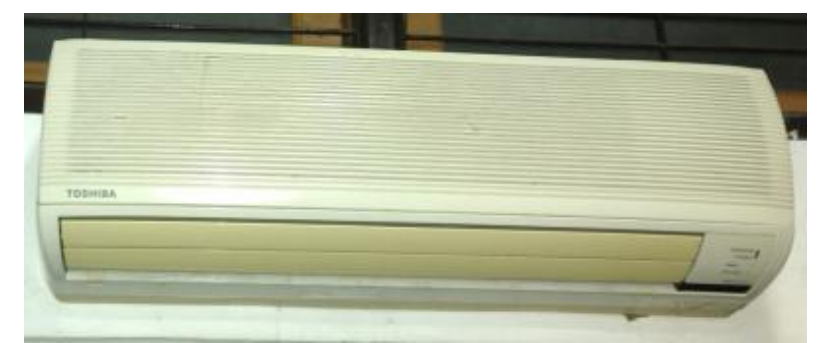

Gambar 11 AC split Toshiba RAS-13YKX

Hasil data penelitian per-hari mengunakan metode observasi terdapat pada table 3 . Dapat dilihat terdapat perbedaan penggunaan KWh sebelum dan sesudah menggunakan SELACTION.

Tabel 3 Hasil Data Rerata Penelitian Per-Hari

\begin{tabular}{lllllll}
\hline \multirow{2}{L}{$\begin{array}{l}\text { Lama } \\
\text { penelitian }\end{array}$} & $\begin{array}{l}\text { KWh } \\
\text { (sebelum } \\
\text { mengunakan } \\
\text { alat) }\end{array}$ & $\begin{array}{l}\text { KWh } \\
\text { (mengunakan } \\
\text { alat) }\end{array}$ & $\begin{array}{l}\text { Kondisi di Luar Ruangan } \\
\text { Sebelum }\end{array}$ & \multicolumn{3}{l}{ Sesudah } \\
\hline $\mathrm{H} 1$ & 1.76 & 1.53 & 30 & 77,65 & 30,6 & 73,7 \\
$\mathrm{H} 2$ & 1.71 & 1.53 & 30 & 77 & 30 & 68,3 \\
$\mathrm{H} 3$ & 1.77 & 1.64 & 30 & 58,5 & 30,5 & 56,4 \\
$\mathrm{H} 4$ & 1.86 & 1.35 & 31 & 60 & 30,5 & 59,8 \\
$\mathrm{H} 5$ & 1.78 & 1.55 & 29,6 & 71,6 & 30,2 & 71,6 \\
$\mathrm{H} 6$ & 1.84 & 1.36 & 30 & 54,6 & 30,8 & 54 \\
$\mathrm{H} 7$ & 1.65 & 1.46 & 30 & 55,6 & 30 & 55,6 \\
\hline
\end{tabular}




\section{Uji Komparatif dengan Uji t}

Uji komparatif digunakan untuk mencari dan mengetahui hubungan antara variabel dalam panelitian. Uji komparatif yang dilakukan merupakan uji komparatif dari dua kelompok berpasangan, karena berasal dari kelompok data yang sama, yaitu, sebelum menggunakan alat dan sesudah menggunakan alat. Sebelum melakukan uji komparatif, dilakukan Uji Normalitas Data. Uji ini dilakukan untuk mengetahui normalitas distribusi data, dengan melihat hasil dari uji Shapiro-Wilk. Uji ShapiroWilk dipilih karena jumlah sampel kurang dari 50. Jika data yang diperoleh terdistribusi normal, $p>$ 0,05, maka uji hipotesis kompatatif yang dilakukan adalah dengan Uji t berpasangan (parametrik).

Uji t adalah jenis uji statistika yang digunakan untuk membandingkan rata-rata dua kelompok yang saling berpasangan. Sampel berpasangan dapat diartikan sebagai sebuah sampel yang mendapat 2 perlakuan atau pengukuran yang berbeda pada subjek yang sama, yaitu pengukuran sebelum dan sesudah dilakukan sebuah treatment. Syarat jenis uji ini adalah: (a) data berdistribusi normal; (b) kedua kelompok data adalah dependen (saling berhubungan/berpasangan); dan (c) jenis data yang digunakan adalah numeric dan kategorik (dua kelompok). Jika tidak, maka digunakan uji alternatifnya, yaitu uji Wilcoxon (uji nonparametrik). Hasil analisis dari uji komparatif akan didapatkan nilai $p$. Nilai $p$ selanjutnya digunakan untuk menguji hipotesis dan menarik kesimpulan apakah ada atau tidaknya hubungan antara variabel. Jika nilai $p<0,05$, maka terdapat adanya perbedaan rerata yang bermakna antara dua kelompok data. Pengujian komparatif dilakukan dengan menggunakan program SPSS 16.0 for windows.

Tabel 4 Kondisi Lingkungan Tempat Penelitian

\begin{tabular}{llcccc}
\hline Kategori & Variabel & Mean & Median & SB & $\begin{array}{c}\text { Minimum - } \\
\text { Maksimum }\end{array}$ \\
\hline Periode I & Jumlah Individu (orang) & 2,43 & 3 & 1,58 & $0-6$ \\
& Laptop (Buah) & 2,32 & 3 & 1,52 & $0-5$ \\
& Solder (Buah) & 0,24 & 0 & 0,43 & $0-1$ \\
& Lampu (Buah) & 3,26 & 4 & 1,56 & $0-4$ \\
& Suhu di luar ruangan $\left({ }^{\circ} \mathrm{C}\right)$ & 30,43 & 30,5 & 0,92 & $28,5-32,7$ \\
& Kelembaban Udara $(\% \mathrm{RH})$ & 64,97 & 60 & 11,59 & $50-89$ \\
Periode II & 2,43 & 3 & 1,58 & $0-6$ \\
& Jumlah Individu (orang) & 2,32 & 3 & 1,52 & $0-5$ \\
& Laptop (Buah) & 0,24 & 0 & 0,43 & $0-1$ \\
& Solder (Buah) & 3,26 & 4 & 1,56 & $0-4$ \\
& Lampu (Buah) & 30,5 & 30,6 & 0,96 & $28,1-33,7$ \\
& Suhu di luar ruangan $\left({ }^{\circ} \mathrm{C}\right)$ & 62,78 & 58 & 10,90 & $50-89$ \\
\hline
\end{tabular}

Dari tabel di atas dapat dilihat bahwa kondisi lingkungan pada periode I (sebelum menggunakan alat) sama dengan kondisi pada lingkungan pada periode II (setelah menggunakan alat).

Pada Periode I. Dari hasil tersebut dapat diketahui rerata jumlah individu dalam ruang penelitan 3 orang dengan kisaran 0 - 6 orang. Rerata penggunaan laptop dalam ruang penelitian 3 buah, dengan kisaran $0-5$ buah. Rerata penggunaan solder berada pada kisaran $0-1$. Rerata penggunaan lampu sebesar 4 buah dengan kisaran 0 - 4 buah. Rerata suhu lingkungan $30,43 \pm 0,92$ ${ }^{\circ} \mathrm{C}$. Rerata kelembangan udara lingkungan $60 \%$ dengan kisaran $50-89 \%$.

Pada Periode II. Dari hasil tersebut dapat diketahui rerata jumlah individu dalam ruang penelitan 3 orang dengan kisaran 0 - 6 orang. Rerata penggunaan laptop dalam ruang penelitian 3 buah, dengan kisaran $0-5$ buah. Rerata penggunaan solder berada pada kisaran $0-1$. Rerata penggunaan lampu sebesar 4 buah dengan kisaran 0 - 4 buah. Rerata suhu lingkungan $30,5 \pm 0,96{ }^{\circ} \mathrm{C}$. Rerata kelembangan udara lingkungan $58 \%$ dengan kisaran $50-89 \%$.

Tabel 5 Uji t Sebelum dan Sesudah Menggunakan SELACTION

\begin{tabular}{|c|c|c|c|c|c|}
\hline Kelompok & Jumlah & Rerata $\pm S B$ & $\begin{array}{l}\text { Perbedaan } \\
\text { Rerata } \pm S B\end{array}$ & IK 95\% & $p$ \\
\hline Periode I & $\begin{array}{l}7 \\
7\end{array}$ & $1,77 \pm 0,07$ & $0,28 \pm 0,15$ & $0,14-0,42$ & 0,003 \\
\hline
\end{tabular}

Periode I adalah sebelum menggunakan alat, dan periode II adalah setelah menggunakan alat. Dari hasil tabel di atas diperoleh nilai $p 0,003(p<0,005)$, artinya terdapat perbedaan rerata penggunaan $\mathrm{kWh}$ yang bermakna sebelum dan sesudah penggunakan alat. Tingkat kepercayaan 
sebesar 95\% bahwa jika pengukuran dilakukan pada AC, selisih sebelum menggunakan alat dengan setelah menggunakan alat adalah antara 0,14-0,42. Berdasarkan uji statistic didapatkan bahwa dengan menggunakan alat dapat melakukan penghematan energi listrik sebesar 15,82 \%.

\section{SIMPULAN DAN SARAN}

Simpulan yang dapat diambil berdasarkan hasil perancangan, pengujian, perhitungan, dan pengukuran unjuk kerja sistem perangkat keras desain model sistem control AC (Air Conditioning) menggunakan mikrokontroler ATmega16 yang telah dihasilkan sudah bekerja sesuai dengan tujuan yang hendak dicapai dalam penelitian ini. Perangkat keras kontrol SELACTION (safety energi listrik air conditioning) mampu melakukan aktif/nonaktif oautomatis pada AC split, yang diinstruksikan dengan keberadan manusia mengunakan sensor Passive Infrared Receiver (PIR). Kontrol Air Conditioning automatis dapat mengatur suhu sesuai dengan kebutuhan pengguna, menggunakan sensor suhu LM35 berbasis mikrokontroler ATmega16 dan dimensi dari kontrol air conditioning automatis adalah $11 \times 12 \times 2,3 \mathrm{~cm}$. Penghematan energi listrik dapat dilakukan dengan mengunakan SELACTION (safety energi listrik air conditioning) pada AC split Toshiba RAS-13YKX. Penghematan energi listrik yang di dapatkan sebesar $15,82 \%$ dan perangkat keras SELACTION terpisah dari $A C$ yang ingin di control (portable).

Berdasarkan simpulan dan hasil pembahasan, maka dapat disampaikan saran agar sensor input untuk mengontrol $A C$ sebaiknya ditambah agar memperkuat akurasi keberadan manusia, seperti menambah sensor panas tubuh manusia pada perangkat keras kontrol SELACTION.

\section{DAFTAR PUSTAKA}

[1] G. H. Hundy, A. R. Trott, and T. C. Welch, Refrigeration and Air-Conditioning. 2008.

[2] American Society of Heating Refrigerating and Air-Conditioning Engineers Inc., "2016 ASHRAE Handbook - Heating, Ventilating, and Air-Conditioning Applications (I-P Edition)," Am. Soc. Heating, Refrig. Air-Conditioning Eng. Inc., 2016.

[3] C. Bujoreanu and M. Benchea, "Experimental study on HVAC sound parameters," in IOP Conference Series: Materials Science and Engineering, 2016.

[4] Refrigeration, Air Conditioning and Heat Pumps. 2016.

[5] G. F. Hundy, A. R. Trott, and T. C. Welch, "Air Conditioning Methods and Applications," in Refrigeration, Air Conditioning and Heat Pumps, 2016.

[6] I. G. M. N. Desnanjaya, I. A. D. Giriantri, and R. S. Hartati, "Rancang Bangun Sistem Control Air Conditioning Automatis Berbasis Passive Infrared Receiver," in Prosiding Conference on Smart-Green Technology in Electrical and Information System, 2013.

[7] D. Almanda, K. Krisdianto, and E. Dermawan, "MANAJEMEN KONSUMSI ENERGI LISTRIK DENGAN MENGGUNAKAN SENSOR PIR DAN LM 35," elektum, 2017.

[8] A. G. S. Utama, N. M. Janani, S. Silfiana, T. N. A. Wulandari, and B. Budiningtyas, "Automation Of Electrical Energy Savings System: Hemat Listrik, Hemat Biaya," Ekuitas J. Pendidik. Ekon., 2018.

[9] P. Martínez, J. Ruiz, C. G. Cutillas, P. J. Martínez, A. S. Kaiser, and M. Lucas, "Experimental study on energy performance of a split air-conditioner by using variable thickness evaporative cooling pads coupled to the condenser," Appl. Therm. Eng., 2016.

[10] N. Nethaji and S. T. Mohideen, "Energy conservation studies on a split airconditioner using loop heat pipes," Energy Build., 2017.

[11] S. Bartien, "Puil 2011," DirJen Ketenagalistrikan, 2011.

[12] H. Jones, "INVERTER CONTROLLED AIR CONDITIONERS.," Aust. Refrig. Air Cond. Heat., 1986.

[13] S. Bartien, "Persyaratan Umum Instalasi Listrik 2000," DirJen Ketenagalistrikan, 2000.

[14] ATMEL, "8-bit XMEGA A Microcontroller," Writing. 2009.

[15] Desnanjaya. Supartha, "Rancang Bangun Alat Modul Praktikum Mikrokontroler di STMIK STIKOM Indonesia,” S@CIES, vol. 7, no. 1, pp.61-68, 2016.

[16] Atmel, "ATmega48A/PA/88A/PA/168A/PA/328/P," AVR Microcontrollers, 2015.

[17] I. G. M. N. Desnanjaya and I. B. A. I. Iswara, "Trainer Atmega32 Sebagai Media Pelatihan Mikrokontroler Dan Arduino," J. Resist. (Rekayasa Sist. Komputer), 2018.

[18] Atmel, "Datasheet ATmega32 ( L )," San Jose, CA, USA, 2503Q-AVR-02/11, 2011.

[19] Digilife, "Energymeter Digilife DL8," 2019. [Online]. Available: http://digilifeweb.com/Alat-UkurUji/Electrical-Tester/Energymeter-Digilife-DL8. [Accessed: 26-Jun-2019]. 